\title{
Analysis of Lower Body Change in Active Body Positions of Varying Degrees
}

\author{
Ping XIAO ${ }^{a, b}$, Susan P. ASHDOWN ${ }^{c}$ \\ ${ }^{a}$ Fashion Institute, Donghua University, Shanghai, P.R. China; \\ ${ }^{\mathrm{b}}$ Key Laboratory of Clothing Design and Technology, Ministry of Education, Shanghai, China; \\ ${ }^{c}$ Department of Fiber Science \& Apparel Design, Cornell University, Ithaca NY, USA
}

\section{Abstract}

http://dx.doi.org/10.15221/13.301

\begin{abstract}
Recently three-dimensional body scanners have been used to analyze changes in body measurements in active positions. The purpose of this study was to analyze the change in body surface measurements of knee and hip in active positions in greater detail, comparing a standing posture to postures when lifting the right leg to 5 different heights. Six female participants, average age 22.8, were scanned for this study. Starting from the knee point and hip point, 20 landmarks were placed on each participant at $5 \mathrm{~cm}$ incrementswhile in the standing position. The distance between each adjacent point was compared and analyzed in scans of the 6 different postures. The angles and distances between knee central points and knee side points were also compared. As the leg angles increased, the distance between each adjacent point located on the side knee decreased, the distance on the central knee increased, and the distance on the central hip increased with different amounts of increase/decrease depending on the distance of the landmark from the joint center. The height and angle between the knee central point and knee side point increased with increasing leg angle. The results from this analysis provide a more precise indication of active leg positions in order to better design active pants.
\end{abstract}

Keywords: Body scanning, human body motion, body surface change

\section{Introduction}

In order to provide comfort in active clothing, it is necessary create pattern shapes that allow the wearer to function and move unrestricted by their clothing systems ${ }^{[1]}$. That is, clothing should provide sufficient space for the moving body. This can be particularly difficult for garments made of woven fabrics.

The fit of clothing has been studied by researchers for decades, but few studies addressed changes in body measurements in active positions prior to the development of the 3D body scanner. With the technology of 3-D body scanning improving, several researchers have used 3-D body scanner as a tool to examinethe body surface measurement changes in different postures ${ }^{[2,3]}$. However, these studies generally measured overall changes in surface measures, for example overall girth changes, width changes,or limb lengths. The movements in these studies are also minimal, comparing simple movements such as walking, sitting, and reaching with standard anthropometric movements.In this research, we measure changes for more extreme movements, and we examine the changes across small increments in order to measure the body surface changes more precisely. These change values or ratios will be used to design the optimal ease values for activewear pants. Therefore, the objective of this paper to analyze the change in body surface measurements of knee and hip in active positions in greater detail, comparing a standing posture to postures with the right leg lifted to 5 different heights.

\section{Background}

\section{Studies on human movements and clothing fit}

The balance between human movement and clothing fit is critical for designers, especially when designing functional garments made with woven fabrics that do not stretch. Previous research focuses on narrow ranges of movement and only capturesoverall changes of body measurements. Kirk and Ibrahim (1966) measured the body surface changes at the knee, the seat, the back and the elbows in three dynamic postures: bending, stretching and sitting ${ }^{[4]}$. Lotens (1989) defined seven body postures which can be found in daily life, and quantified the changes in clothing ease needed for each movement ${ }^{[5]}$. Lee and Ashdown (2005) used a 3D body scanner to measure the body surface changes of upper body in three active postures, shoulder flexion, scapula protraction, and scapula elevation ${ }^{[6]}$. Choi and Ashdown (2010) selected four daily postures: a standing posture, a 120 knee bend posture, a 
one pace stepping posture, and a sitting posture with a 90 knee bend, to measure difference in lower body measurements by using a 3D body scanner ${ }^{[7]}$. Wang et al. (2011) analyzed the difference of 30 body measurements in 17 dynamic postures ${ }^{[8]}$. These 17 postures were divided into waist, elbow, shoulder, hip and knee joint movements. In previous research, Lee, Choi and Ashdown used manually placed landmarks and the 3D body scanner to extract the body surface changes. Kirk and Ibrahim measured skin stretch manually on the body by marking directly on the skin and measuring the changes with a measuring tapeto calculate body change in active postures. In all these research findings, body dimensions were observed to change with body movement, and change values and ratios were reported. However, no studies using the 3D body scanner to measure body changes at a higher range of movement, or in a more detailed set of measures that will isolate the actual areas of skin stretch have been reported.

\section{Methodology Participants}

Participants for this study were six American University female students, aged from 21 to 25 (average 22.83), whose hip girths were between $90.3 \mathrm{~cm}$ and $106.2 \mathrm{~cm}$ and who wore regular Misses sized 10 to 12 pants in US sizing.

Participantswere scanned while wearing their own bra and panties, using a Human Solutions Vitus XXL whole body scanner. This 3D body scanner only detectsgeometric features of the body, not color or texture variation. In order to analyze the changes in body surface measurements of knee and hip in active positions in greater detail, manual landmarks were set on each participant in the anthropometric standing position (Posture 1) to be captured by the 3D scanner. Then, each participant was scanned in seven postures. Finally, 3D body data were extracted by human solution software and converted to a format which could be processed by the Geomagic software. Measurements of girth, length between two landmarks and body angles were obtained by using the Geomagic software.

\section{Measurement processes}

\section{Measuring postures}

Each participant was scanned in the anthropometric standing position (Posture 1), the standing posture with the weight distributed equally on both feet (Posture 2) and five active postures when lifting the right leg to five different heights (Posture 3 to 7 ), as shown in Figure 1.The difference in stepping height between two adjacent active postures was $12 \mathrm{~cm}$.

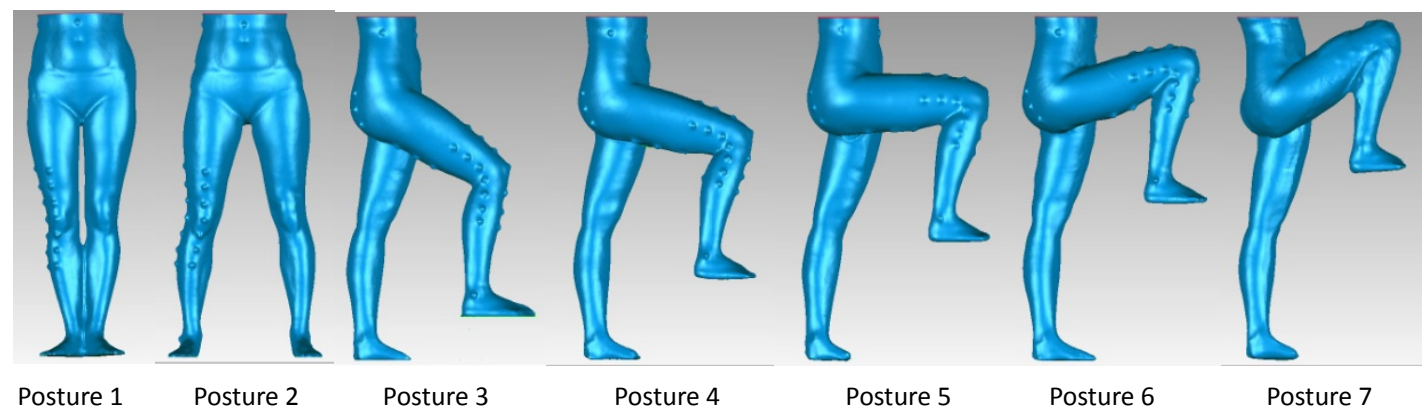

Figure 1 the Sevendynamic postures used in the study

When each participant was in posture 6, two of the landmarks on the back surface of the leg were so close that they overlapped. It was not possible to accurately locate the positions of the overlapped landmarks, so there is missing data for these overlapped areas.

In order to place the landmarks for this study, knee and hip joint landmarks were identified based on ASTM D 5219-0 ${ }^{[9]}$ (2009) for each participant. Then 6additional landmarks were placed on each participant at $5 \mathrm{~cm}$ incrementson a central line originating from the knee point. In the frontal view, these landmarks were set to divide the front right knee into two parts, as shown in Figure 2(a). Another 7 landmarks were marked at $5 \mathrm{~cm}$ increment centered on a line originating from the side knee point, as shown in Figure 2(b). Starting from the hip point, 5 landmarks were marked on each participant at $5 \mathrm{~cm}$ increments in the anthropometric standing position. These five landmarks divided the right lower body into two parts, as shown in Figure 2(c). Four additional landmarks were then marked at the front, side and back waist and right ankle point. Figure 2 shows the location and descriptions of the landmarks.In order to maintain reliability across the full set of scans, all landmarks were set by the same researcher. 
The landmarks used were half sphere dimensional markers provided by Human Solutions for 3D measuring (Choi and Ashdown, 2011). An anthropometer was used to set the vertical distance of the landmarks and to keep side landmarks and front landmarks in the same horizontal level. In order to describe clearly the distances between points, the landmarks were named, as shown in Figure 3. A set ofwooden square, each one XX mm thick were used to adjust the height.In order to help standardize the position, two footprints were placed, one on the scan platform and the other on the top wooden square.

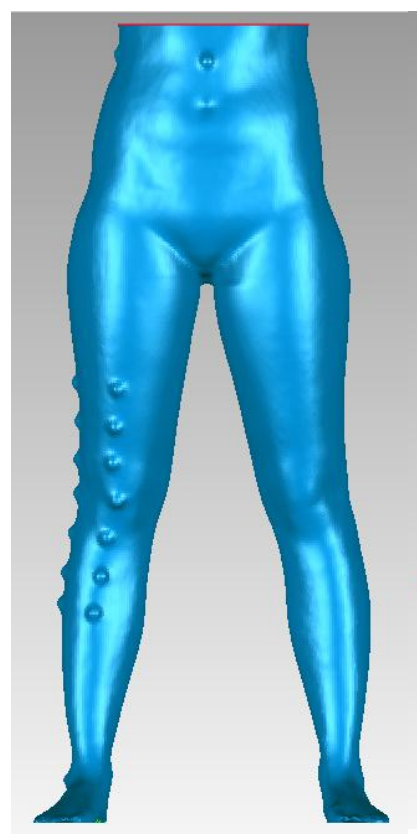

(a) Front

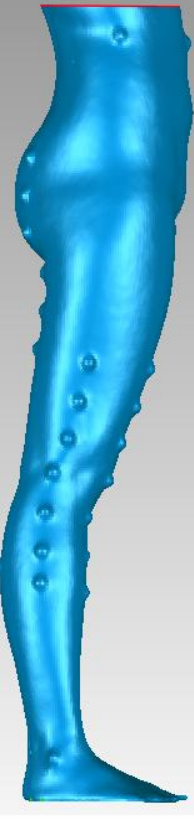

(b) Side

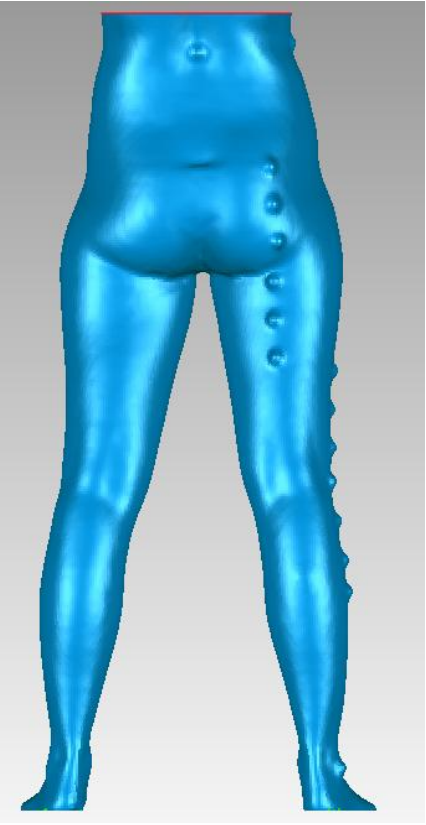

(c) Back

Figure 2 Landmarks Positions

\section{Measuring items}

Thirteen dimensions of the lower body were automatically measured from the scan in the standing posture using the Human Solution sizing software Scanworxs, and twenty-one dimensions of the lower body were manually measured from the surface of the 3D scans based on the identified landmarks in the seven active postures using Geomagic software. Three proportional measurements were created to analyze the lower body shape. Body measurements and their locations are shown in Table 1 and figure 3. Variable KCR refers to the ratio of knee height to crotch height. Variable HWR refers to the ratio of hip height to waist height. Variable KWR refers to the ratio of knee height to waist height.

As the landmarks were dimensional spheres, a landmark point needed to be generated on the surface of the scan to allow accurate surface measurements. The landmark points were generated and labeled by visually choosing the top center point of each dimensional marker and projecting this point down to the surface of the body by transposing it to the known height of the marker. The landmark bump was then removed from the scan and the resulting void filled so that the dimension of the marker would not distort the measurement. Finally, virtual measuring tools were used to measure the body using these landmarked locations on the scan. The positions of these landmarks were exported from Geomagic and imported into the software Polyworks in order to measure the surface curve length between two adjacent side knee points. 
Table 1 Body measurements taken for the study

\begin{tabular}{|c|c|c|c|c|c|c|c|}
\hline Height & $\begin{array}{l}\text { Body } \\
\text { height }\end{array}$ & $\begin{array}{l}\text { Waist } \\
\text { height }\end{array}$ & $\begin{array}{l}\text { Buttock } \\
\text { height }\end{array}$ & $\begin{array}{l}\text { Crotch } \\
\text { height }\end{array}$ & $\begin{array}{l}\text { Knee } \\
\text { height }\end{array}$ & $\begin{array}{l}\text { Ankle } \\
\text { height }\end{array}$ & \\
\hline Girth & $\begin{array}{l}\text { Waist } \\
\text { girth }\end{array}$ & $\begin{array}{l}\text { Buttock } \\
\text { girth }\end{array}$ & $\begin{array}{l}\text { Crotch } \\
\text { length }\end{array}$ & $\begin{array}{l}\text { Thigh girth } \\
\text { (horizontal) }\end{array}$ & Knee girth & calf girth & $\begin{array}{l}\text { Ankle } \\
\text { girth }\end{array}$ \\
\hline \multirow{16}{*}{ Length } & & \multicolumn{6}{|c|}{ Front center knee } \\
\hline & & FKL3 & FKL2 & FKL1 & FKL-1 & FKL-2 & FKL-3 \\
\hline & Point 1 & FP3 & FP2 & FP1 & FP & FP-1 & FP-2 \\
\hline & Point 2 & FP2 & FP1 & FP & FP-1 & FP-2 & FP-3 \\
\hline & & \multicolumn{6}{|c|}{ Side center knee } \\
\hline & & SKL3 & SKL2 & SKL1 & SKL-1 & SKL-2 & SKL-3 \\
\hline & Point 1 & SP3 & SP2 & SP1 & SP & SP-1 & SP-2 \\
\hline & Point 2 & SP2 & SP1 & SP & SP-1 & SP-2 & SP-3 \\
\hline & & \multicolumn{4}{|c|}{ Back center hip } & & \\
\hline & & HPL2 & HPL1 & HPL-1 & HPL-2 & HPL-3 & \\
\hline & Point 1 & HP2 & HP1 & HP & HP-1 & HP-2 & \\
\hline & Point 2 & HP1 & $\mathrm{HP}$ & HP-1 & HP-2 & HP-3 & \\
\hline & & \multicolumn{2}{|c|}{ Crotch } & \multicolumn{2}{|c|}{ Waist } & & \\
\hline & & $\mathrm{FCL}$ & $\mathrm{BCL}$ & WFL & WBL & & \\
\hline & Point 1 & WFP & $\mathrm{CP}$ & WFP & WSP & & \\
\hline & Point 2 & $\mathrm{CP}$ & WBP & WSP & WBP & & \\
\hline Ratio & KCR & HWR & KWR & & & & \\
\hline
\end{tabular}
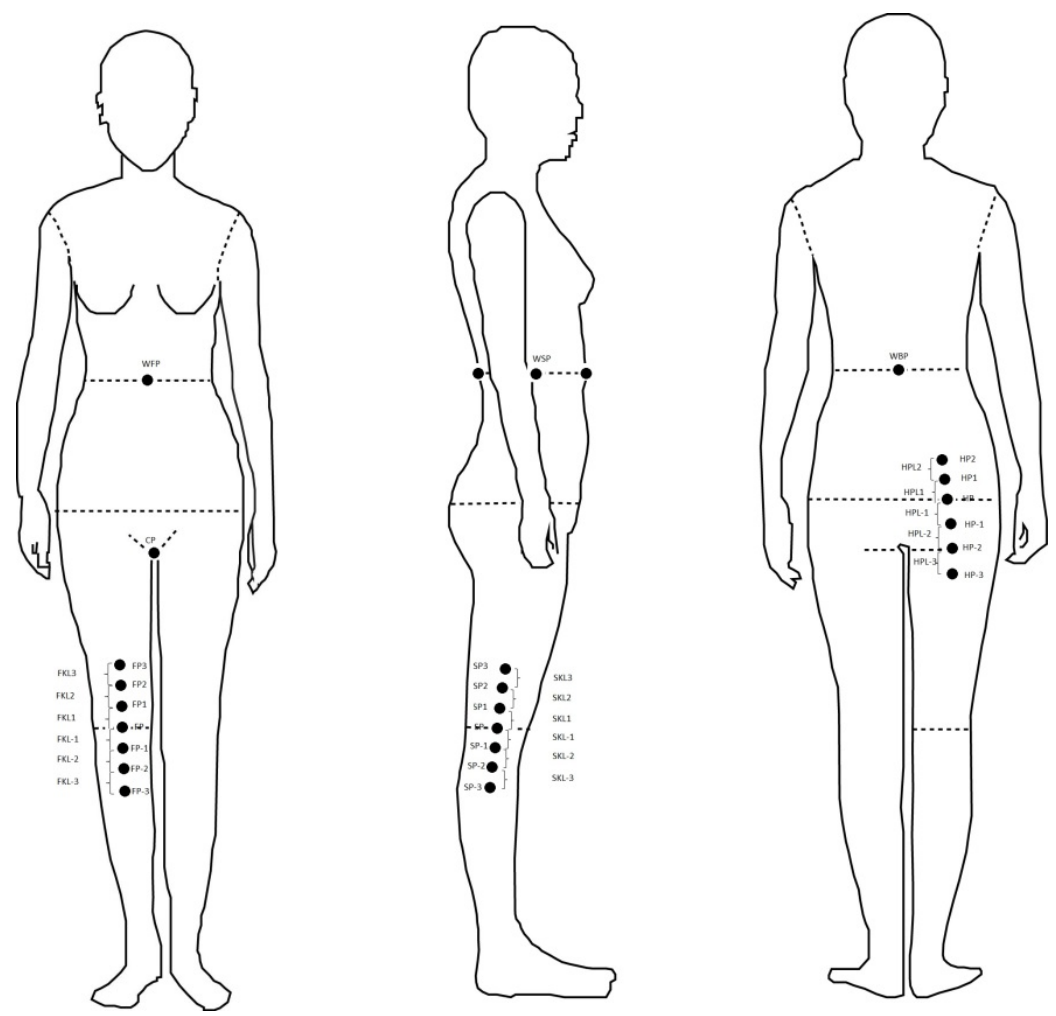

Figure 3 the locations of body measurements 


\section{Data analysis}

Data were analyzed using SPSS. Measurements from the five postures from the 3D body scans were compared to identify the significant differences among the postures using a LSD test. Values and the rate of body surface change among the different postures were calculated.

\section{Results and discussion}

Table 2 shows basic information of these participants and descriptive statistics of basic 3D body measurements from the standing posture.Average waist and hip girth measurements were $70.28 \mathrm{~cm}$ and $95.60 \mathrm{~cm}$.

Table 2 Descriptive statistics of 3D scan measurements in standing pose (Units: $\mathrm{cm}, \%$ )

\begin{tabular}{lcccc}
\hline & Mean & Minimum & Maximum & Std. Deviation \\
\hline Age & 22.83 & 19.00 & 29.00 & 3.31 \\
Body height & 158.22 & 155.50 & 163.60 & 2.88 \\
Waist height & 100.15 & 98.10 & 103.70 & 2.07 \\
Hip height & 79.23 & 76.20 & 81.80 & 2.27 \\
Crotch height & 70.17 & 66.50 & 72.60 & 2.58 \\
Knee height & 42.23 & 40.60 & 43.60 & 1.21 \\
Ankle height & 6.67 & 5.90 & 7.20 & 0.50 \\
Crotch length & 74.95 & 70.50 & 81.90 & 4.07 \\
FCL (Crotch length front) & 35.03 & 32.50 & 38.00 & 1.94 \\
BCL (Crotch length rear) & 39.90 & 37.00 & 43.90 & 2.48 \\
Waist girth & 70.28 & 65.40 & 80.40 & 5.36 \\
Hip girth & 95.60 & 90.30 & 106.20 & 5.93 \\
Thigh girth (horizontal) & 54.82 & 51.10 & 60.00 & 3.88 \\
Knee girth & 37.52 & 35.60 & 40.20 & 1.78 \\
Calf girth & 36.00 & 34.30 & 38.10 & 1.43 \\
Ankle girth & 22.40 & 21.10 & 24.60 & 1.16 \\
KCR & 60.21 & 59.37 & 61.05 & 0.60 \\
HWR & 79.11 & 77.36 & 80.56 & 1.19 \\
KWR & 42.17 & 41.22 & 42.90 & 0.63 \\
\hline
\end{tabular}

\section{Body surface change}

In order to compare the difference in body surface measurements between active postures and the standing posture, we calculated the data on the average values and ratios of dimensional change from scanned data for the five active postures comparing each posture with posture 2 , the standing posture. In order to provide data relevant to the design of activewear pants, we analyzed the body surface change from three aspects; the front knee, the side knee, and the central hip and crotch. 
Table 3multiple comparisons of surface changing (LSD) (unit: $\mathrm{cm}$ )

\begin{tabular}{|c|c|c|c|c|c|c|c|c|c|c|c|c|}
\hline \multirow{2}{*}{ Items } & \multicolumn{2}{|c|}{ Posture3 } & \multicolumn{2}{|c|}{ Posture4 } & \multicolumn{2}{|c|}{ Posture5 } & \multicolumn{2}{|c|}{ Posture6 } & \multicolumn{2}{|c|}{ Posture7 } & \multirow{2}{*}{ F-value } & \multirow{2}{*}{$p$-value } \\
\hline & Mean & S.D. & Mean & S.D. & Mean & S.D. & Mean & S.D. & Mean & S.D. & & \\
\hline FKL3 & 0.05 & 0.14 & 0.12 & 0.19 & 0.21 & 0.11 & 0.36 & 0.17 & 0.56 & 0.34 & 5.93 & 0.002 \\
\hline FKL2 & 0.49 & 0.19 & 0.80 & 0.22 & 1.02 & 0.30 & 1.14 & 0.28 & 1.34 & 0.31 & 9.19 & 0.000 \\
\hline FKL1 & 1.37 & 0.18 & 1.91 & 0.31 & 2.44 & 0.39 & 2.63 & 0.39 & 2.79 & 0.52 & 14.46 & 0.000 \\
\hline FKL-1 & 1.67 & 0.53 & 2.20 & 0.61 & 2.67 & 0.66 & 2.93 & 0.66 & 3.21 & 0.85 & 4.96 & 0.004 \\
\hline FKL-2 & 0.91 & 0.25 & 1.13 & 0.23 & 1.29 & 0.39 & 1.44 & 0.34 & 1.55 & 0.29 & 4.27 & 0.009 \\
\hline FKL-3 & 0.16 & 0.17 & 0.25 & 0.18 & 0.28 & 0.15 & 0.30 & 0.12 & 0.30 & 0.12 & 0.91 & 0.472 \\
\hline SKL3 & -0.10 & 0.13 & -0.16 & 0.19 & -0.26 & 0.18 & -0.22 & 0.19 & -0.25 & 0.21 & 0.81 & 0.530 \\
\hline SKL2 & -0.32 & 0.23 & -0.38 & 0.18 & -0.36 & 0.17 & -0.43 & 0.16 & -0.30 & 0.23 & 0.44 & 0.780 \\
\hline SKL1 & -0.50 & 0.14 & -0.85 & 0.28 & -1.03 & 0.32 & -1.04 & 0.40 & -0.88 & 0.47 & 2.46 & 0.071 \\
\hline SKL-1 & -0.54 & 0.26 & -0.96 & 0.28 & -1.24 & 0.52 & -1.50 & 0.47 & -1.57 & 0.56 & 5.71 & 0.002 \\
\hline SKL-2 & -0.34 & 0.11 & -0.64 & 0.22 & -0.67 & 0.11 & -0.76 & 0.09 & -0.79 & 0.25 & 6.93 & 0.001 \\
\hline SKL-3 & -0.30 & 0.15 & -0.30 & 0.15 & -0.44 & 0.17 & -0.51 & 0.18 & -0.53 & 0.21 & 2.45 & 0.073 \\
\hline HPL2 & 0.26 & 0.15 & 0.31 & 0.22 & 0.27 & 0.22 & 0.21 & 0.24 & 0.05 & 0.18 & 1.27 & 0.313 \\
\hline HPL1 & 0.12 & 0.17 & 0.19 & 0.17 & 0.16 & 0.22 & 0.16 & 0.26 & 0.14 & 0.19 & 0.07 & 0.990 \\
\hline HPL-1 & 2.68 & 2.42 & 3.11 & 2.70 & 3.56 & 3.01 & 3.68 & 3.06 & 4.03 & 3.34 & 0.16 & 0.956 \\
\hline HPL-2 & 2.40 & 1.02 & 2.99 & 1.21 & 3.36 & 1.52 & 3.73 & 1.27 & 3.77 & 1.36 & 0.99 & 0.438 \\
\hline HPL-3 & 2.35 & 1.20 & 2.84 & 1.62 & 3.33 & 1.74 & 3.57 & 1.87 & 4.22 & 1.51 & 1.00 & 0.433 \\
\hline
\end{tabular}

\section{Comparison of knee changes in different postures}

Figure 4 shows the ratios of change in length between adjacent landmarks on the front knee surface. The ratios of all length changes are positive values, that is, all lengths between two adjacent landmarks in the active postures increase from the corresponding value from the standing posture. The change rate increases as the height of the raised legis increased. When landmarks are closer to the central front knee landmark, the surface change ratios are greater. Otherwise, the surface change values are smaller when landmarks are further from the central front knee point. Using multiple comparisons LSDreveals no significant differences in the change values between the FP-2 landmark and the FP-3 landmark in the five active postures, and significant differences in the change values among the other five landmarks on the front knee(Table 3). The change values between adjacent landmarks below the central front knee pointare greater than that of the landmarks above the central front knee point. Among all of the length changes, FKL-1 length in posture 7 increased about $57.84 \%$, FKL1 length increased about $52.77 \%$, FKL-2 length increased about $32.91 \%$, and FKL2 length increased about $25.95 \%$.

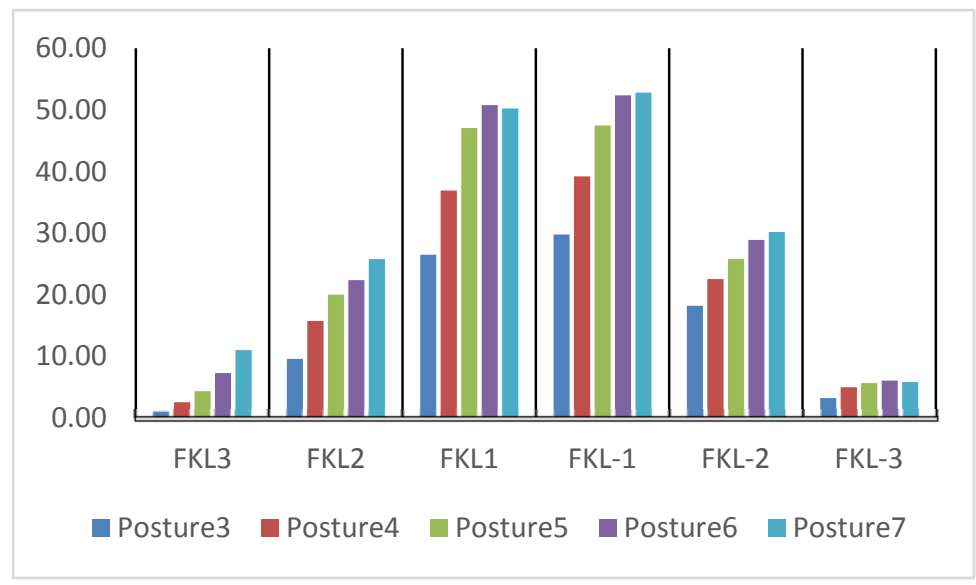

Figure 4 Body surface change ratios on the front knee surface (unit:\%) 
The length change values between adjacent landmarks on the side knee surface are shown in Figure 5 . In this case we see that all length changes are negative values, that is, all lengths between two adjacent landmarks in active postures decrease. The change values increasewhen the range of motion of the posture increases. When landmarks are closer to the central side knee point, the surface change values increase. Otherwise, the surface change values are smaller when landmarks are further from the central side knee point. Through using multiple comparisons LSD, we see that there are only significant differences in the change values of SKL-1 and SKL-2 in the five active postures, and there are no significant differences in change values among any other landmarks (Table 3 ). The change values between adjacent landmarks below the central side knee point are larger than those of landmarks above the central side point. Among all of the length changes, SKL-1 length in posture 7 decreased about $30.73 \%$, SKL1 length decreased about $18.81 \%$, SKL-2 length decreased about $14.12 \%$, and SKL2 length decreased about $7.25 \%$.

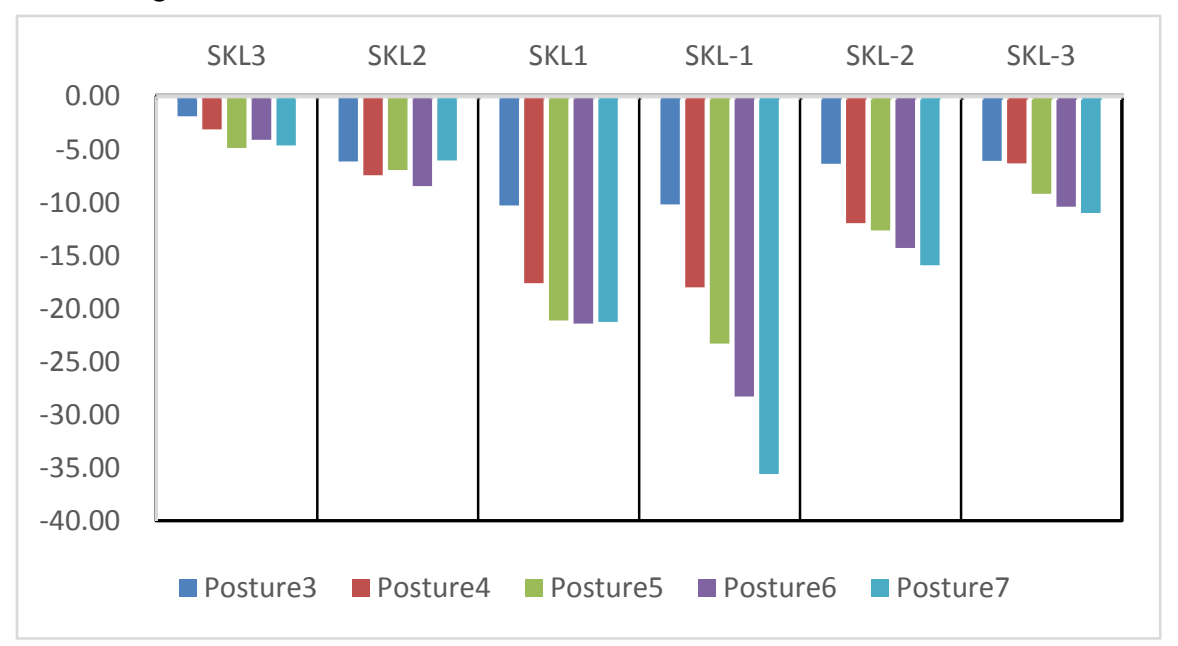

Figure 5 Body surface change ratios on the side knee surface (unit :\%)

Figure 6 shows the change of length valuesbetween adjacent landmarks on the central hip surface. All length changes are positive values, that is, all lengths between two adjacent landmarks in active postures increase. Using multiple comparisons LSDwe see that there are no significant differences in change values in any of the five active postures. Because two landmarks above the hip point and the hip landmark were attached on each participant's underwear, and the fabric didn't change totally with the skin changes,the length between adjacent landmarks under the hip point increased more than those above the hip point. The valuesincreased as the intensity of the posture increased. At the same time, the changing values are greater for the landmarks that are further from the hip joint under the hip level.

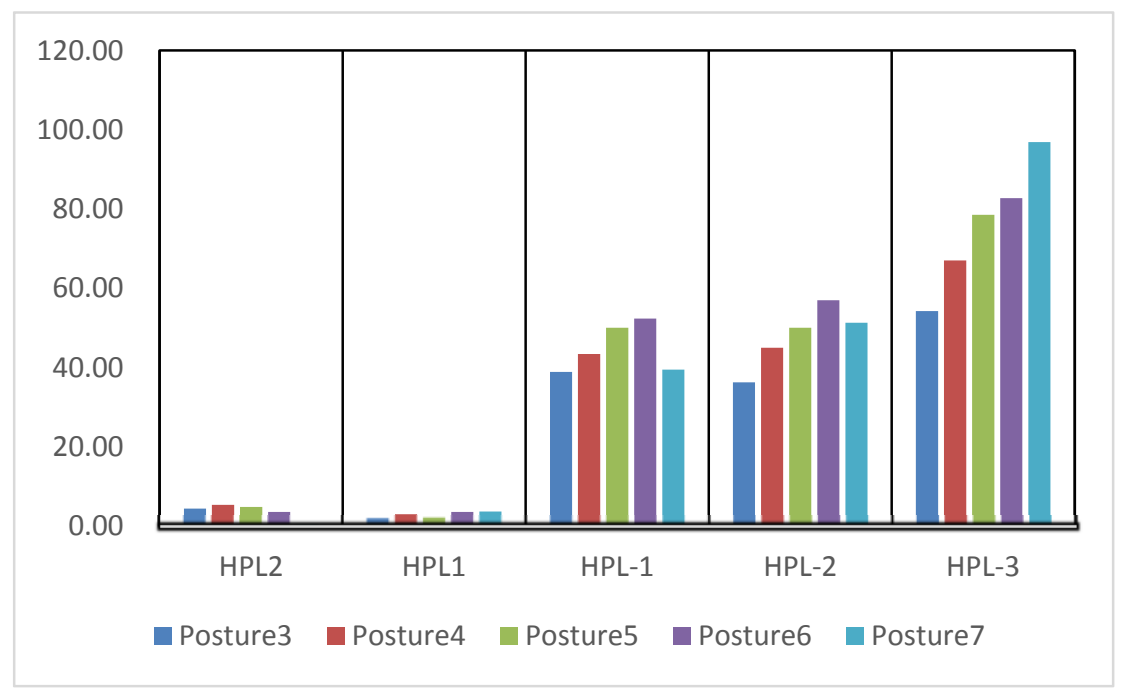

Figure 6 Body surface change ratios on the central hip surface ( unit: \%) 
The change of functional line on the lower body

All of these changes will affect the fit of active pants in active positions, so these changes values are provided to designers for designing activewear pants that will move and fit well for outdoor sports. In order to provide information for patternmaking for activewear pants, we calculated the average values from three different positions.

The length changing values between two adjacent landmarks are different. Through calculating these changing values, the changing mean values of the whole front knee line between FKP3 and FKP-3 in different postures are shown in Table 4 . We see that the changing mean value is increasing while the intensity of the posture is increased. The smallest mean value was about $4.06 \mathrm{~cm}$ in posture 3 , and the biggest value was about $11.61 \mathrm{~cm}$ in posture 7 .

Table4 change of front knee line (unit: $\mathrm{cm}$ )

\begin{tabular}{lcccc}
\hline & Mean & Minimum & Maximum & Std. Deviation \\
\hline Posture 3 & 4.65 & 4.06 & 5.65 & 0.62 \\
Posture 4 & 6.41 & 5.49 & 7.61 & 0.84 \\
Posture 5 & 7.91 & 6.96 & 9.05 & 0.74 \\
Posture 6 & 8.83 & 7.75 & 10.52 & 1.03 \\
Posture 7 & 9.75 & 8.74 & 11.61 & 1.03 \\
\hline
\end{tabular}

Table 5 shows the changing mean values of the whole side knee line between SKP3 and SKP-3 in different postures. The length of this side knee line decreases as the intensity of the posture is increased. However the changing values did not decrease when participants were in extreme postures. The mean value was about $4.47 \mathrm{~cm}$ while participants were in posture 6 . The largest changing value was about $6 \mathrm{~cm}$ in posture 7 , and the smallest changing value was about $1.76 \mathrm{~cm}$ in posture 3 .

Table 5 change of side knee line (unit: $\mathrm{cm}$ )

\begin{tabular}{lcccc}
\hline & Mean & Minimum & Maximum & Std. Deviation \\
\hline Posture 3 & -2.09 & -2.69 & -1.76 & 0.32 \\
Posture 4 & -3.29 & -4.72 & -2.67 & 0.78 \\
Posture 5 & -3.99 & -5.74 & -3.47 & 0.90 \\
Posture 6 & -4.47 & -5.63 & -3.69 & 0.73 \\
Posture 7 & -4.33 & -6.09 & -3.00 & 1.03 \\
\hline
\end{tabular}

Table 6 shows the changing mean values of the whole hip line between HP2 and HP-3 in different postures. The mean value was about $12.69 \mathrm{~cm}$ while participants were in posture 7 .

Table 6 change of hip line (unit: $\mathrm{cm}$ )

\begin{tabular}{lcccc}
\hline & Mean & Minimum & Maximum & Std. Deviation \\
\hline Posture 3 & 7.96 & 6.72 & 9.45 & 1.07 \\
Posture 4 & 9.57 & 8.03 & 11.15 & 1.17 \\
Posture 5 & 10.88 & 8.78 & 12.39 & 1.26 \\
Posture 6 & 11.62 & 9.74 & 13.32 & 1.35 \\
Posture 7 & 12.69 & 10.55 & 16.15 & 2.32 \\
\hline
\end{tabular}




\section{Conclusions}

Placing landmarks on the body surface of participants make it possible to measure the change in a localized area of the body by using 3-D body scanners. 3D measurements extracted from body scans of participants in active body positions are accurate and reliable (Lee and Ashdown, 2005; Choi and Ashdown, 2011) ${ }^{[6,10]}$. Using these methods the change in body surface measurements of the knee and hip in active positions have been studied in greater detail in this paper.

Through comparing lower body surface measurements in a standing posture with measurements in 5 different active postures, it was found that the change values increased while the intensity of the posture increased, for example FKL2 length in posture 3 increased about $9.56 \%$, the changing rate of FKL2 in posture 4 is $15.72 \%$, the rate of FKL2 in posture 5 is $20 \%$, the rate of FKL2 in posture 6 is $22.35 \%$, and the rate of FKL2 in posture 7 is $25.78 \%$. Using the one way T-test in SPSS software, we found significant changes for the lower body in dynamic postures,but multiple comparisons LSD showed no significant differences for some localized area of the lower body in dynamic postures. For the localized area of the side knee, there were only significant differences of the change values of SKL-1 and SKL-2 in the five active postures, and there were no significant differences of change ratios among other four positions.

In this study the knee area is separated into front knee area and side knee area. Through comparing the change in body surface measurement values in each dynamic posture, we found that the closer a landmark position is to the active joint, the larger the changing surface measurement value. The average change in value of FKL3 is $1.07 \%$ in posture 3 , FKL2 is $9.56 \%$, FKL1 is $26.50 \%$, FKL-1 is $29.76 \%, \mathrm{FKL}-2$ is $18.19 \%$, and FKL-3 is $3.22 \%$. At the same time, the change rate between adjacent landmarks under knee joint is bigger than that of landmarks up the central front point. The change ratios of body surface on the side knee are negative values, that is, all lengths between two adjacent landmarks in active postures decrease, while all lengths between two adjacent landmarks on the surface of front knee are increased. When participants are in extreme postures, length of some body area will not change.

These results can give direction to the fit design of functional pants, especially for the design of knee darts and the ease balance in different dynamic postures. These values can also be used to design patterns for tight pants with the appropriate stretch fabric. In the future study, a dynamic block patternmaking will be developed for active pants. A wear test and fit test will be provided to test the accuracy and the reliability of this patternmaking method.

\section{Funding}

This work was supported by "the Fundamental Research Funds for the Central Universities".

\section{References}

1. Ashdown, S.P., Sizing in clothing. 2007: WOODHEAD PUBLISHING LIMITED.

2. liu C., K.R., Body scanning of dynamic posture. International Journal of Clothing Science and Technology, 2006. 18(3): p. 166-178.

3. Ashdown, S.P. and H. Na, Comparison of 3-D Body Scan Data to Quantify Upper-Body Postural Variation in Older and Younger Women. Clothing and Textiles Research Journal, 2008. 26(4): p. 292-307.

4. Wm. Kirk, J., and S.M. Ibrahim, Fundamental Relationship of Fabric Extensibility to Anthropometric Requirements and Garment Performance. Textile Research Journal, 1966. 36: p. 37-47.

5. Lotens, W.A., Optimal design principles for clothing systems, in Research Study group on Biomedical Research Aspects of Military Protective Clothing. 1989, NATO: Brrussels. p. 1701-1715.

6. Lee, J. and S.P. Ashdown, Upper Body Surface Change Analysis using 3-D Body Scanner. Journal of the Korean Society of Clothing and Textiles, 2005. 29(12): p. 1595-1607.

7. Ashdown, S.C.S.P., Application of Lower Body Girth Change Analysis Using 3D Body Scanning to Pants Patterns. Journal of the Korean Society of Clothing and Textiles, 2010. 34(6): p. 955-968.

8. Wang, Y.J., et al., Body measurements of Chinese males in dynamic postures and application. Applied Ergonomics, 2011. 42(6): p. 900-912.

9. ASTM, ASTM D5219-09 Standard Terminology Relating to Body Dimensions for Apparel Sizing, 2009.

10. Choi, S. and S.P. Ashdown, $3 D$ body scan analysis of dimensional change in lower body measurements for active body positions. Textile Research Journal, 2011. 81(1): p. 81-93. 